\title{
Research
}

Mieke Vermandere, Yoo-Na Choi, Heleen De Brabandere, Ruth Decouttere, Evelien De Meyere, Elien Gheysens, Brecht Nickmans, Melanie Schoutteten, Lynn Seghers, Joachim Truijens,

Stien Vandenberghe, Sofie Van de Wiele, Laure-Anne Van Oevelen and Bert Aertgeerts

\section{GPs' views concerning spirituality and the use of the FICA tool in palliative care in Flanders:}

\author{
a qualitative study
}

\begin{abstract}
Background

According to recent recommendations,

healthcare professionals in palliative care should be able to perform a spiritual history-taking. Previous findings suggest that the FICA tool is feasible for the clinical assessment of spirituality. However, little is known about the views of GPs on the use of this tool.

To identify points of agreement about spirituality as it applies to health care and to make recommendations to advance the delivery of qualified spiritual care in palliative care, a Consensus Conference was held in 2009 in Pasadena, California, US. The participants agreed upon the following recommendations:
\end{abstract}

\section{Aim}

To provide a solid overview of the views of Flemish GPs concerning spirituality and the use of the FICA tool for spiritual history-taking in palliative care.

\section{Design and setting}

Qualitative interview study in Flanders, Belgium.

\section{Method}

Twenty-three GPs participated in a semistructured interview. The interviews were analysed by thematic analysis, which includes line-by-line coding and the generation of descriptive and analytical themes.

\section{Results}

The interviewees stated that they would keep in mind the questions of the FICA tool while having a spiritual conversation, but not use them as a checklist. The content of the tool was generally appreciated as relevant, however, many GPs found the tool too structured and prescribed, and that it limited their spontaneity. They suggested rephrasing the questions into spoken language. The perceived barriers during spiritual conversations included feelings of discomfort and fear, and the lack of time and specific training. Factors that facilitated spiritual conversations included the patients' acceptance of their diagnosis, a trusting relationship, and respect for the patients' beliefs.

\section{Conclusion}

A palliative care process with attention focused on the patient's spirituality was generally perceived as a tough but rewarding experience. The study concludes that the FICA tool could be a feasible instrument for the clinical assessment of spirituality, provided that certain substantive and linguistic adjustments are made. Additional research is needed to find the most suitable model for spiritual history-taking, in response to the specific needs of GPs.

\section{Keywords}

general practice; medical history taking; palliative care; spirituality.

\section{INTRODUCTION}

All healthcare professionals should be trained in doing a spiritual screening or history as part of their routine history and evaluation. Healthcare providers should adopt and implement structured assessment tools to facilitate documentation of needs and evaluation of outcomes of treatment.'

The EAPC (European Association of Palliative Carel taskforce on spiritual care in palliative care has agreed upon the following working definition of spirituality, based on the Consensus Conference in the US:

Spirituality is the dynamic dimension of human life that relates to the way persons (individual and community) experience, express and/or seek meaning, purpose and transcendence, and the way they connect to the moment, to self, to others, to nature, to the significant and/or the sacred. "2

M Vermandere, MD, research assistant; Y-N Choi, MD, GP trainee; $\mathbf{H}$ De Brabandere, MD, GP trainee; R Decouttere, MD, GP trainee; E De Meyere, MD, GP trainee; E Gheysens, MD GP trainee; B Nickmans, MD, GP trainee; M Schoutteten, MD , internal medicine trainee; L Seghers, MD, GP trainee; J Truijens, MD, GP S Van de Wiele, MD, GP trainee; L-A Van Oevelen, MD, GP trainee; B Aertgeerts, MD, PhD, head of department, Katholieke Universiteit Leuven, Department of General Practice, Leuven, Belgium. trainee; $\mathbf{S}$ Vandenberghe, MD, GP trainee;
It also highlighted that the spiritual field is multidimensional:

1. Existential challenges (for example, questions concerning identity, meaning, suffering and death, guilt and shame, reconciliation and forgiveness, freedom and responsibility, hope and despair, love and joyl.

2. Value-based considerations and attitudes I what is most important for each person, such as relations to oneself, family, friends, work, things nature, art and culture, ethics and morals, and life itself).

3. Religious considerations and foundations (faith, beliefs and practices, and the relationship with God or the ultimate). '2

Most seriously ill patients and their GPs consider it important that physicians attend to patients' spiritual concerns. ${ }^{3}$ Patients justify spiritual assessment on the basis of importance of spirituality in life and health. They affirm that physicians are helpful when legitimising their spiritual concerns. ${ }^{4}$ However, almost three-quarters of patients with advanced cancer report that their spiritual needs are supported minimally or not at all by the medical system. ${ }^{5}$

Most GPs see it as their role to identify and assess their patients' spiritual needs, despite perceived barriers such as lack

\section{Address for correspondence}

Mieke Vermandere, KU Leuven, Department of General Practice, Kapucijnenvoer 33, Block J, Box 7001, 3000 Leuven, Belgium.

E-mail: Mieke.Vermandereamed.kuleuven.be Submitted: 9 February 2012; Editor's response: 26 March 2012; final acceptance: 9 May 2012. (c)British Journal of General Practice This is the full-length article lpublished online 1 Oct 2012) of an abridged version published in print. Cite this article as: $\mathbf{B r} \mathbf{J}$ Gen Pract 2012; DOI: 10.3399/bjgp12X656865 


\section{How this fits in}

Recent findings suggest that the FICA tool is a feasible tool for the clinical assessment of spirituality. However, little is known about the views of GPs regarding the use of this tool in palliative care. According to this study findings, the FICA tool can be used as a guide for spiritual history taking by GPS, not as a checklist. However, a rephrasing of the questions is needed for more comfortable use in practice.

of time and specific training. ${ }^{6}$ However, they struggle with spiritual language and experience feelings of discomfort and fear that patients will refuse to engage in the discussion. ${ }^{6}$ Little is known about the views of GPs on assessment tools for spiritual history taking, especially in palliative care.

The FICA spiritual history tool, created by Christina Puchalski in 1996 in collaboration with three primary care physicians, provides a way for the clinician to efficiently integrate the open-ended questions into a standard medical history (Box 1). Recent findings suggest that the FICA tool is a feasible tool for the clinical assessment of spirituality.

The aim of this article is to provide a solid overview of the views of Flemish GPs concerning spirituality and the use of the FICA tool for spiritual history taking in palliative care.

\section{METHOD}

Flemish GPs with accreditation and a minimum of 3 years experience as a GP were invited to participate in this study. They

\section{Box 1. FICA tool ${ }^{7}$}

\section{F: Faith, belief, meaning}

- Do you consider yourself spiritual or religious?

- Do you have spiritual beliefs that help you cope with stress?

- What gives your life meaning?

\section{I: Importance and Influence}

- What importance does your faith or belief have in your life?

- On a scale of 0 (not important) to 5 (very important), how would you rate the importance of faith/belief in your life?

- Have your beliefs influenced you in how you handle stress?

- What role do your beliefs play in your healthcare decision making?

\section{C: Community}

- Are you a part of a spiritual of religious community?

- Is this of support to you and how?

- Is there a group of people you really love or who are important to you?

\section{A: Address in care}

- How would you like your healthcare provider to use this information about your spirituality as they care for you? were chosen by location, in the surroundings of the Catholic University of Leuven. Twelve researchers conducted face-to-face semistructured interviews with these GPs for their Master's thesis, under the supervision of their advisor and co-advisor. They used an interview schedule of 11 open-ended questions.

The FICA tool was translated into Dutch through forward-backward translation. This translation method begins with a version of the tool in English, the language in which it was originally developed. This version was given to professional translators who translated the tool into Dutch. Then, another professional translated the Dutch version back into English (back translation) and the two English versions were compared. All participating GPs received the Dutch version of the FICA tool and the EAPC working definition of spirituality a few days before the interview. The demographic data of the GPs were collected before the start of the interview. The interview questions were based on the literature, supplemented by ideas gathered in a brainstorming session, and finally approved by all the authors. All the interviews were recorded and transcribed verbatim.

Thematic analysis was used as a method for the analysis of the semi-structured interviews. Thematic analysis is a tried and tested method that preserves an explicit and transparent link between the conclusions and the text of the primary data. Thematic analysis has three stages: the line-byline coding of the text, the development of 'descriptive themes', and the generation of 'analytical themes'. ${ }^{8}$ While the development of descriptive themes remains 'close' to the primary data, the analytical themes represent a stage of interpretation whereby the reviewers 'go beyond' the primary data and generate new interpretive constructs, explanations or hypotheses. After careful inductive coding (both descriptive and interpretive), the authors located recurring themes.

\section{RESULTS}

Fifty-eight GPs were invited to participate in this study. Twenty-three of them accepted the invitation and were interviewed. The interviews took 1-2 hours. The reasons for non-participation were lack of time ( $n=28)$, no interest ( $n=5)$, and not meeting the inclusion criteria ( $n=2)$. The demographic data are shown in Table 1.

Table 2 presents a thematic matrix of the following results. Box 2 summarises the evaluation of the FICA tool by the GPS in this study. 


\section{Table 1. Demographic data of the GPs interviewed}

$n(\%)$

\begin{tabular}{lc}
\hline Sex & $13(56.5)$ \\
Male & $10(43.5)$ \\
Female & \\
\hline Location of GP practice & $14(61)$ \\
Rural & $7(30.5)$ \\
Urban & $2(8.5)$ \\
Mixed & \\
\hline Type of GP practice & $10(43.5)$ \\
Solo & $7(30.5)$ \\
Duo & $4(17.5)$ \\
Group & $2(8.5)$ \\
GPs under one roof &
\end{tabular}

\begin{tabular}{lc}
\hline & Mean (range) \\
\hline Age, years & $46.9(30-63)$ \\
\hline Years of practice experience & $20.2(4-36)$ \\
\hline Number of palliative patients/year & $4.9(0-20)$ \\
\hline
\end{tabular}

\section{What is spirituality?}

The GPs interviewed expressed a broad range of views on spirituality. Some of the GPs agreed with the definition of spirituality given in the US consensus document, ${ }^{1}$ in which spirituality is associated with the search for meaning in life, a higher being, life after death, love, wonder, gratitude, and people's basic orientation in life:

'[Spirituality is] a personal attitude to life, an outlook on life, ... [...] Spirituality is, to a certain extent, the time that you invest in the way you relate to things. '(GP 18)

The interviews revealed that these GPs considered religion to be a potential, but not mandatory component of spirituality:

'Religion is one of the forms, I think, in which spirituality can be expressed or defined. Thus I think it is a subset of the larger set we call "spirituality". Uhh ... beyond that, I don't really see any other distinctions. But I think that you can perfectly well be spiritual in a non-religious way. That is also possible. And, yes, it seems to me that there are many different mixed forms of spirituality.' (GP 6)

Several GPs considered spirituality to be a dynamic dimension: a person's spirituality can change throughout life. A difference in spiritual experience was noted between younger and older generations:

At certain times in your life, spirituality is more important: when you marry, when you have children ... the great turning points in your life. For the average 20-year-old student, it is somewhat less important. But the moment you hear the cancer diagnosis, it once again becomes important. [...] They also say this about religiosity: in times of war, the churches are full.' (GP 8)

\section{Spiritual history taking}

Only somewhat less than half of the interviewees would take the initiative to start up a spiritual conversation, while the other GPs would leave it up to the patient. Responding to hints or noting signals from the patient were techniques the GPs would use to start the conversation. Raising the issue of end-of-life care was another way to stimulate openness:

When the patient brings it up, then we further pursue the issue, ... then we start talking about it.' (GP 3)

So I try to sense whether people are thinking about it ... about that end, and what comes after.' (GP 6)

Most GPs agreed that the timing and the course of a spiritual conversation are determined by the patient. The spontaneity of these moments was frequently underlined:

In his physical, psychic, and spiritual experience, [the patient] is the captain of his own ship.' (GP 1)

Many GPs preferably conversed in private with their patients about spirituality, at the patient's home. Spirituality received more attention in the palliative care process when physical and psychological aspects of care are less prominent.

Discussing spiritual issues with patients was perceived to be a value in the course of a care pathway. These issues were clearly distinguished from other dimensions in care, for example, the physical dimension:

When people feel the meaning of life or they feel the warmth ... I mean, when they feel the friendship, or the family that is supporting them. Or, indeed, the spiritual life - when that is to some extent opened up ... [...] That is perhaps 10 times more important than your [...] taking their blood pressure, because I think they will not be put at ease by that. I think they will rather be reassured by a different conversation. I think that this point is extremely important ... absolutely!' (GP 20)

\section{Barriers in spiritual history taking}

Many GPs experienced their own emotions as a possible barrier in spiritual conversations with patients. Supposed knowledge about the patients' beliefs could hinder the communication, as does also a lack of privacy with the patient. A closed attitude and not accepting the palliative diagnosis were patient factors that can be barriers.

Lack of spiritual education and the emphasis on 'cure' rather than on 'care' were perceived to be shortcomings in medical training. Many GPs had not mastered the spiritual language, and they had the impression that the patients also had difficulties in finding their words:

Well, uh, for myself ... the fact that you don't know many words for talking about it. I feel that we have very little ... I mean that I have very little language for talking about these things. ' (GP 2)

Western society and its unfamiliarity with spirituality was another barrier. The 


\section{Table 3. Thematic matrix: views of the GPs interviewed concerning spiritual care in palliative care}

\begin{tabular}{|c|c|c|c|c|c|}
\hline & \multicolumn{2}{|l|}{ Definition of spirituality } & Role of religion & \multicolumn{2}{|c|}{ Spirituality as a dynamic process } \\
\hline \multirow[t]{2}{*}{ What is spirituality? } & $\begin{array}{l}\text { - Broad vision of spirituality } \\
\text { - Affirmation of US definition'1 } \\
\text { - Questions about meaning, life } \\
\text { after death }\end{array}$ & \multicolumn{2}{|c|}{$\begin{array}{l}\text { - Religion is a potential, but not } \\
\text { mandatory component of spirituality }\end{array}$} & \multicolumn{2}{|c|}{$\begin{array}{l}\text { - Spirituality is variable } \\
\text { - Older and younger people have different } \\
\text { spiritual experiences }\end{array}$} \\
\hline & $\begin{array}{l}\text { Initiation of spiritual } \\
\text { conversations }\end{array}$ & How? & Setting & & Why? \\
\hline Spiritual history-taking & Physician factors & Patient factors & \multicolumn{2}{|c|}{ GP-patient relationship factors } & Contextual factors \\
\hline $\begin{array}{l}\text { Barriers in spiritual } \\
\text { history-taking }\end{array}$ & Physician factors & Patient factors & \multicolumn{2}{|c|}{ GP-patient relationship factors } & Contextual factors \\
\hline \multirow[t]{2}{*}{$\begin{array}{l}\text { Facilitating factors in } \\
\text { spiritual history-taking }\end{array}$} & $\begin{array}{l}\text { - Practice experience } \\
\text { - Being receptive for patients } \\
\text { spirituality } \\
\text { - Mental preparation for a } \\
\text { spiritual conversation }\end{array}$ & $\begin{array}{l}\text { - Accepting palliative diagnosis } \\
\text { - Symptom control }\end{array}$ & \multicolumn{2}{|c|}{$\begin{array}{l}\text { - Trusting relationship } \\
\text { - Respect for unique person } \\
\text { - GP showing human side }\end{array}$} & - Positive influence of family \\
\hline & GP as spiritual care giver & Threats in spiritual care & \multicolumn{3}{|l|}{ Influence on GP } \\
\hline Spiritual care & $\begin{array}{l}\text { - GP should be a spiritual care } \\
\text { giver } \\
\text { - GP is not required to be a } \\
\text { spiritual care giver } \\
\text { - Referral to patient's relatives } \\
\text { or professional spiritual care } 9\end{array}$ & $\begin{array}{l}\text { - Lack of time } \\
\text { - Lack of formal spiritual } \\
\text { education }\end{array}$ & \multicolumn{3}{|c|}{$\begin{array}{l}\text { - Rewarding experience } \\
\text { - Stressful experience }\end{array}$} \\
\hline
\end{tabular}

interviewees often felt spirituality was a taboo topic, and described Western society as superficial:

'Sexuality used to be a taboo, but that's no longer the case. Now you can talk about it. But faith and spirituality, that's something that is no longer talked about. It's a new taboo. Uh, you're backwards and wacky if you talk about that.' (GP 7)

\section{Facilitating factors in spiritual history taking}

Several physician-related facilitating factors were identified: having experience in palliative care, the GP's own interest in spirituality, being receptive to the patient's spirituality, and preparing mentally for spiritual conversations. The interviewees also mentioned patient-related facilitating factors, such as acceptance of the palliative diagnosis and adequate symptom control.

A trusting relationship between the GP and the patient was perceived to be an important facilitating factor and, for some GPs, it was even perceived to be a prerequisite for spiritual conversations. Respecting the patient's beliefs and personality was another factor. GPs who were able to show their human side seemed to have fewer difficulties discussing spiritual issues:

Not only sitting there and prescribing medication, but truly being able to talk as one human being to another and to show another side of ourselves. Not only as a doctor in the sense of being a care giver in terms of medical support, but also as a friend, as someone who ..., yes, in palliative care we do indeed forge a tremendously strong bond with the patient.' (GP 4)

\section{Spiritual care}

Opinions about the role of the GP in spiritual care were divided. Some GPs stated that spiritual care is not their task. These GPs preferably referred patients to their relatives (that is, family or cultural society). Secondarily, they would refer patients to professional spiritual care givers: 


\section{Box 2. Evaluation of the FICA tool by the GPs interviewed}

\section{Positive comments}

- Useful questions

- Relevant questions

- Complete instrument

- Neutral instrument

- Adds new themes in spiritual conversations

\section{Negative comments}

- Survey style

- Limits spontaneity

- Too prescribed

- Too categorical

- Does not leave enough opportunity to ask for specific needs

- Could cause resistance in patients

\section{Suggested adjustments}

- Rephrasing questions into spoken language

- Adjusting questions to local society

- Less strict division into four categories

- Avoiding the word 'spirituality' (too modern)

- Avoiding the word 'stress' (could be related to work)

- Adding questions about the patient's attitude towards death, and about what he/she leans on when things get difficult

\section{Use of FICA tool in daily practice}

- FICA as guide for spiritual conversations

- FICA most useful for young or inexperienced physicians

- Documenting the patient's answers in a computerized patient database

- Broader use of FICA (other professional groups, other settings, other patient groups)
So I think that you really need to be careful about putting everything in little pigeonholes. A hat rack is not a bad thing, of course, but I think you need to be very careful about hanging a whole lot of very specific things on it.' (GP 1)

'The problem is that it will come across as artificial if you ask the patient questions with the question list beside you. It needs to be spontaneous. Because this is not the usual doctor-patient communication.

Discussing a patient's spirituality by means of an instrument could cause resistance in the patient, according to some GPs:

'I think that the patient would then say: "But doctor, what are you getting at?".' (GP 5)

Many GPs would rephrase the FICA questions into spoken language. This could make the tool more useful in daily patient contacts:

"It's easier for me to ask: "Jef, do you want the priest to drop by again? Would you like that?", than to say: "Are you a member of a spiritual community?". '(GP 2)

think in the first place that it is not my personal responsibility to start up a conversation with the patient about 'spiritual care'. So is that my role? Is that my task? Is that my duty? I don't think so.' (GP 22)

However, the majority of interviewees considered the GP a suitable spiritual care provider. In particular, they attributed an informative and guiding role to the GP:

' am in any case convinced that the GP should also play this role, in the palliative phase, that this must be one of the GP's responsibilities. And then it kind of depends on the situation as to who finally performs the role or who is able to take it upon him or herself, but anyway, we are indeed one of the possibilities, it seems to me. ' (GP 6)

It seemed important that the GPs can refer to other care providers for specialised spiritual care.

\section{Evaluation of the FICA tool}

Many GPs disapproved the survey-style of the instrument, because it could limit the spontaneity of the discussion. The tool was described several times as being too prescribed and categorical, and not leaving enough space for the patient to bring up specific needs:
Many interviewees considered the tool as a guide or instrument a physician can keep in mind while having a spiritual conversation:

'I wouldn't say that we [...] work through the whole list, [...] point by point... but it certainly is a useful guideline.' (GP 23)

Some GPs were interested to test the FICA tool in daily practice, others were not. It was put forward that this tool could be most useful for young or starting GPs. Others wanted to integrate the FICA into their computerised patient database:

"I think that in general it can be valuable for people who are not yet so familiar with spirituality, or who find it a little difficult to deal with it or to bring it up in conversation. (GP 23)

The use of the FICA tool should not necessarily be limited to physicians. Other professional groups can also benefit from it. Neither should its use be limited to patients receiving palliative care:

'These are questions [...] that can also be asked by a person's friends, family members or nurses. It's not per se a list 
that can or must be used only by the doctors.' (GP 4)

You could also use it [...] with non-palliative patients.' (GP 5)

\section{DISCUSSION}

\section{Summary}

The GPs interviewed expressed a broad, dynamic view of spirituality, considering religion a potential, but not mandatory component. They perceived spiritual conversations with patients receiving palliative care as a value in the course of a care pathway. However, only half of the GPs would take the initiative. The others would rather leave it to the patient, waiting for a spontaneous moment.

Many GPs are hindered by barriers in spiritual conversations, such as uncertainty, fear, lack of time, lack of formal spiritual education, lack of privacy with the patient, and the unfamiliarity of Western society with spirituality. However, they also described factors that can facilitate these conversations, such as the GP's own interest in spirituality, patients accepting the palliative diagnosis, a trusting relationship, and respect for patients' unique beliefs and personality.

The FICA tool was considered a possible guide or instrument that GPs can keep in mind while having spiritual conversations. The content of the tool was generally appreciated as relevant and useful. However, the interviewees identified a few shortcomings of the FICA tool. Many GPs disapproved of the survey style of the instrument, because it could cause resistance in some patients. The questions were perceived as too prescribed and categorical, limiting the physician's spontaneity. Many GPs would rephrase the tool into spoken language for more comfortable use in daily practice. Some GPs were not at all interested in using the FICA tool.

\section{Strengths and limitations}

According to the authors' knowledge, this is the first qualitative investigation of GPs' views on the use of the FICA tool in palliative care. It was accomplished due to the cooperation of 14 researchers and 23 GPs. The large number of interviews which led to data saturation and the good teamwork among the researchers are two obvious strengths of this study.

The 12 researchers who interviewed the GPs were not familiar with spirituality in end-of-life care before the study started. This is an advantage in qualitative research, because these investigators are not biased by their knowledge of the topic. The interview schedule was prepared under the supervision of an advisor and co-advisor who were more experienced in spiritual care to avoid lack of depth in the interview questions.

The large group of researchers can be seen as an advantage, as well as a disadvantage. This was managed by dividing the tasks of the analysis (such as set-up of the codebook, distinguishing descriptive and analytical themes, and interpretation of results). Before moving on to the following step, a group discussion was held until consensus was reached.

After the line-by-line coding of the text, themes were identified based on their significance related to answering the research questions. The fact that this significance is based on the authors' subjective interpretation could be viewed as a strength, but also as a possible limitation of the study. It cannot be guaranteed that all aspects mentioned by the GPs have been entered into the final results section.

\section{Comparison with the existing literature}

Borneman recommended that additional research on the FICA tool be carried out in typical practice settings. ${ }^{7}$ GPs' views on spirituality and the use of the FICA tool in palliative care were investigated. The broad, dynamic view of spirituality held by the GPs interviewed can be recognised in the definition of spirituality formulated by the EAPC taskforce. ${ }^{2}$ In the current study, as well as in this definition, religion is seen as a potential, but not mandatory component of spirituality.

Only half of GPs interviewed would initiate a spiritual conversation with their patients receiving palliative care. A recent literature review reached the same conclusion. ${ }^{6}$ However, according to the recommendations of Puchalski et al, spirituality should be considered a vital sign' in patients. Just as pain is routinely screened for, so should spiritual issues be a part of routine care.

The barriers the interviewees perceived in spiritual conversations, such as uncertainty, fear, lack of time, and lack of formal spiritual education, are very similar to barriers identified in other studies. ${ }^{6}$ The same can be said about the facilitating factors identified in this study, such as the GP's own interest in spirituality, the patient's acceptance of the palliative diagnosis, a trusting relationship, and respect for the patient's unique beliefs and personality. ${ }^{6}$

Many of the GPs interviewed considered 
the FICA tool to be a feasible instrument for the clinical assessment of spirituality, as previously concluded by Borneman et al. ${ }^{7}$ However, they generally disapproved of the survey-style of the tool. In contrast to the US consensus document, where it is recommended that healthcare providers should adopt and implement structured spiritual assessment tools, the GPs in the current study viewed the categorical structure of the FICA tool as a limitation on their spontaneity. Moreover, they would rephrase the questions into spoken language for more comfortable use in daily practice.

\section{Implications for research and practice}

Following a previous synthesis of the qualitative evidence and the present explorative study concerning the views of GPs on spirituality and the use of the FICA tool in palliative care, additional research is needed in daily palliative practice. ${ }^{6}$ Many spiritual assessment tools are described in literature; for example, INSPIRIT, Spirituality Scale, SPIRIT, and Spiritual Needs Inventory.9-12
Future research should investigate which tool is most feasible for bedside spiritual assessment in a specific care situation. However, it is assumed that the Dutch 'ars moriendimodel' as described by Carlo Leget may be a feasible conversation model for spirituality in palliative care in Flanders, in answer to the suggested adjustments to the FICA tool. ${ }^{13}$ This model was developed by Dutch GPs as an aid to initiating and pursuing spiritual conversations. The diamond shape should cause less resistance than the survey style of the FICA. The questions are formulated in spoken language, without any emphasis on religion. In general, it fits better with GP expectations regarding a spiritual assessment tool than does the FICA. Therefore, the 'diamond model' deserves additional use and evaluation by GPs in palliative care.

More research with the FICA tool is also needed in other settings linpatient as well as outpatient settings), with other healthcare providers (such as nurses and social workers), and with other patient groups such as those with chronic diseases. 


\section{REFERENCES}

1. Puchalski C, Ferrell B, Virani R, et al. Improving the quality of spiritual care as a dimension of palliative care: the report of the Consensus Conference. J Pall Med 2009; 12(10): 885-904

2. European Association of Palliative Care. EAPC survey on spiritual care research priorities. EAPC, 2010. http://uww.eapcnet.eu/Themes/Clinicalcare/ Spiritualcareinpalliativecare.aspx laccessed 3 Sep 2012).

3. Holmes SM, Rabow MW, Dibble SL. Screening the soul: communication regarding spiritual concerns among primary care physicians and seriously ill patients approaching the end of life. Am J Hosp Palliat Care 2006; 23(1): 25-33.

4. Ellis MR, Campbell JD. Patient's views about discussing spiritual issues with primary care physicians. South Med J 2004; 97(12): 1158-1164

5. Balboni TA, Vanderwerker LC, Block SD, et al. Religiousness and spiritual support among advanced cancer patients and associations with end-of-life treatment preferences and quality of life. J C Oncol 2007; 25(5): 555-560.
6. Vermandere M, De Lepeleire J, Smeets L, et al. Spirituality in general practice. A qualitative evidence synthesis. Br J Gen Pract 2011; 61(592): e749-e760.

7. Borneman T, Ferrell B, Puchalski CM. Evaluation of the FICA tool for spiritual assessment. J Pain Symptom Manage 2010; 40(2): 163-173.

8. Thomas J, Harden A. Methods for the thematic synthesis of qualitative research in systematic reviews. BMC Med Res Methodol 2008; 8: 45.

9. VandeCreek L, Ayres S, Bassham M. Using INSPIRIT to conduct spiritual assessments. J Pastoral Care 1995; 49(1): 83-89.

10. Delaney C. The Spirituality Scale: development and psychometric testing of a holistic instrument to assess the human spiritual dimension. J Holist Nurs 2005; 23(2): 145-167.

11. Maugans TA. The SPIRITual history. Arch Fam Med 1996; 5(1): 11-16.

12. Hermann C. Development and testing of the spiritual needs inventory for patients near the end of life. Oncol Nurs Forum 2006; 33(4): 737-744.

13. Leget C. Van levenskunst tot stervenskunst. Over spiritualiteit in de palliatieve zorg. Tielt: Uitgeverij Lannoo NV, 2008. 